\title{
CUIDADO DE ENFERMAGEM NA UNIDADE DE TERAPIA INTENSIVA (UTI): TEORIA HUMANÍSTICA DE PATERSON E ZDERAD
}

\author{
Eliane Regina Pereira do Nascimento ${ }^{1}$ \\ Mercedes Trentini?
}

Nascimento ERP, Trentini M. O cuidado de enfermagem na unidade de terapia intensiva (UTI): teoria humanística de Paterson e Zderad. Rev Latino-am Enfermagem 2004 março-abril; 12(2):250-7.

Atualmente, a disciplina de Enfermagem está sustentada por diversos paradigmas, entre os quais destacamos os da totalidade e os da simultaneidade, por incluírem os principais modelos conceituais e teorias específicas para a prática de Enfermagem. O presente artigo tem como objetivo oferecer subsídios que proporcionem reflexões sobre a possibilidade de as práticas de saúde, nas Unidades de Terapia Intensiva, serem sustentadas pela Teoria Humanística de Paterson e Zderad, a qual faz parte do elenco das concepções do paradigma da simultaneidade. Essa teoria sustenta um cuidado baseado no diálogo que se traduz no encontro genuíno entre e intracuidadores, doentes e seus familiares. Assim sendo, o cuidado nas Unidades de Terapia Intensiva irá além da relação Eu -Isso, para atingir a relação Eu - Tu, ou seja, a subjetividade dos seres.

DESCRITORES: unidades de terapia intensiva; cuidados de enfermagem; comunicação

\section{NURSING CARE AT THE INTENSIVE CARE UNIT (ICU): GOING BEYOND OBJ ECTIVITY}

Nowadays, Nursing is sustained by different paradigms, among which we highlight those related to totality and simultaneity, since these embody the main conceptual models and specific theories for Nursing practice. This study aims to provide elements that will lead to reflections about the possibility of founding health practices at ICUs on the Humanistic Theory of Paterson and Zderad, which is part of the simultaneity paradigm. This theory supports dialogue-based care, which is translated as the genuine encounter between and among caregivers, patients and their families. Thus, ICU care will go beyond the I-That relation, to achieve the $\mathrm{I}$-You relation, that is, the subjectiveness of human beings.

DESCRIPTORS: intensive care unit; nursing care; communication

\section{EL CUIDADO DE ENFERMERÍA LA UNIDAD DE TERAPIA INTENSIVA (UTI): TEORIA HUMANÍSTICA DE PATERSON E ZDERAD}

Actualmente, la disciplina de enfermería está sustentada por diversos paradigmas, entre estos destacamos los de la totalidad y simultaneidad, por incluir los principales modelos conceptuales y teorías específicas para la práctica de Enfermería. Este artículo tiene como objetivo ofrecer aportes para reflexiones sobre las posibilidades de las prácticas de salud, en las Unidades de Terapia Intensiva, sustentadas por la Teoría Humanística de Paterson e Zderad, la que hace parte del conjunto de concepciones del paradigma de la simultaneidad. Esta teoría sustenta un cuidado basado en el diálogo que se traduce en el encuentro genuino entre e intra cuidadores, enfermos y sus familiares. De esta manera, el cuidado en las Unidades de Terapia Intensiva irá de la relación Yo-Eso hacia una relación de Yo-Tú, o sea a la subjetividad de la relación.

DESCRIPTORES: unidades de terapia intensiva; atención de enfermería; comunicación

\footnotetext{
${ }^{1}$ Doutoranda em Filosofia da Enfermagem PEN/UFSC, Professor da Universidade Federal de Santa Catarina, e-mail: eliane@ccs.ufsc.br; ${ }^{2}$ Professor Doutor aposentado da Universidade Federal de Santa Catarina, atuando na Pontifícia Universidade Católica do Paraná, e-mail: mertini@terra.com.br
} 
INTRODUÇÃO

$\boldsymbol{P}$ aradigmas são idéias, normas, valores e convicções compartilhadas por uma comunidade científica $^{(1)}$. Consistem em um conjunto de crenças básicas que guiam a ação. Essas crenças contêm premissas ontológicas, epistemológicas e metodológicas. A premissa ontológica argumenta o que existe no universo que pode ser conhecido, como os "seres" realmente são e qual a finalidade desses "seres". A premissa ou questão epistemológica trata do conhecimento, questiona o relacionamento entre $o$ conhecedor e $o$ que pode ser conhecido. A questão metodológica trata do "como" adquirir conhecimento, de que maneira o investigador pode conhecer a realidade ${ }^{(2)}$.

Neste trabalho, propomo-nos a refletir sobre a possibilidade de o paradigma da simultaneidade contribuir para o cuidado de enfermagem na Unidade de Terapia Intensiva (UTI). O presente estudo é apoiado na teoria humanística de Paterson e Zderad ${ }^{(3)}$ em particular, nas concepções relativas ao ser humano, ambiente, saúde, enfermagem e diálogo ${ }^{(4)}$, e em nossa experiência profissional, na área de terapia intensiva.

Na primeira parte deste trabalho, apresentamos algumas informações sobre como tem sido o cuidado de Enfermagem na UTI. Enfocamos o cuidado aos familiares dos sujeitos internados, tema este de nosso interesse para futura tese de doutorado. Na segunda parte, apresentamos considerações sobre o paradigma da simultaneidade e as bases teórico-filosóficas da teoria selecionada ${ }^{(3)}$ inserida nesse paradigma. Na terceira e última parte, apresentamos os principais conceitos dessa teoria humanística ${ }^{(3)}$ que acreditamos possam ser implementados no cuidado de Enfermagem em UTI.

\section{A UTI E A OBJETIVIDADE DO CUIDADO}

A internação em unidade de terapia intensiva é precedida de comprometimentos orgânicos, presentes e potenciais, que colocam em risco a vida do ser doente. Acreditamos que esse fato tem contribuído para que a assistência de enfermagem, nessa unidade, seja norteada pelo modelo biomédico. Insatisfações com esse modo de cuidar em UTI, nas décadas de 70 e 80, levaram estudiosas de enfermagem nessa área ${ }^{(5-6)}$, a alertar para que seja considerada a existência de outras necessidades tão importantes quanto aquelas pertinentes à esfera física, quando da implementação da assistência. Porém, ao longo de nossa experiência, nessas unidades, temos percebido que, embora exista a necessidade de focalizar o sensível, ainda predomina o cuidado voltado para os aspectos físicos, como controle e manutenção das funções vitais.

O cuidado de enfermagem não pode prescindir do aspecto humanístico e relacional ${ }^{(3)}$. O cuidado não se restringe apenas a uma ação técnica no sentido de fazer, executar um procedimento, mas também no sentido de ser, expresso de forma atitudinal, pois é relacional ${ }^{(7)}$. No entanto, temos observado que esses aspectos são desconsiderados ou pouco valorizados, quando o cuidado se dá num ambiente de terapia intensiva onde a tecnologia e o tecnicismo predominam. O cuidar na UTI é tecnicista e mecânico, desprovido, muitas vezes, dos sentimentos do doente e seus familiares ${ }^{(8)}$.

A vivência em UTI possibilita-nos afirmar que essas unidades possuem algumas características próprias, como: a convivência diária dos profissionais e dos sujeitos doentes com as situações de risco; a ênfase no conhecimento técnico-científico e na tecnologia para o atendimento biológico, com vistas a manter o ser humano vivo; a constante presença da morte; a ansiedade, tanto dos sujeitos hospitalizados quanto dos familiares e trabalhadores de saúde; as rotinas, muitas vezes, rígidas e inflexíveis; e a rapidez de ação no atendimento.

O cuidado de enfermagem se dá, nesse conturbado ambiente de aparelhagens múltiplas, desconforto, impessoalidade, falta de privacidade, dependência da tecnologia, isolamento social, dentre outros. A UTI é totalmente diferente de outras unidades de internação e, sobretudo, do ambiente residencial do sujeito doente e seus familiares. O cuidado ainda é orientado pelo modelo médico, biologicista, cuja atenção está voltada principalmente para o órgão doente, para a patologia e para os procedimentos técnicos, em detrimento dos sentimentos, dos receios do sujeito doente e seus familiares e da forma como vivenciam a situação saúdedoença. Enfim, um modelo guiado pelo paradigma positivista. Esse paradigma, dentre outras características, assume que existe uma realidade que pode ser apreendida por meio de leis e mecanismos naturais imutáveis. A postura básica é reducionista e determinista. $O$ todo é a soma das suas partes; visa ao relacionamento de causaefeito, sem que seja valorizado o diálogo, a presença; o tipo de abordagem utilizada é a quantitativa. 
De acordo com esse modelo, a saúde é vista como "o bom funcionamento dos órgãos ou como a ausência de doença, como objeto de observação e mensuração, nunca como experiência subjetiva, como problema existencial”(9). A doença é vista como danos orgânicos, como um conjunto de sinais e de sintomas, de manifestações físicas. Essa visão não tem lugar para a expressão da subjetividade, para o ser de relações; este não é valorizado.

A internação na UTI rompe bruscamente com o modo de viver do sujeito, incluindo suas relações e seus papéis. A sua identidade fica fortemente afetada. Devido ao grau de gravidade de seu estado, geralmente não é considerado como sujeito capaz de escolher, decidir, opinar, dividir, com direito à expressão e à informação. Muito pouco ou nunca exerce sua autonomia, nem mesmo em relação às atitudes próprias de cada um, como higiene pessoal, alimentação, eliminações, entre outras. Tratase de uma sujeição total ou quase total àqueles que dele cuidam. Deixa de ser um ser singular e transforma-se em um objeto, receptáculo de cuidados técnicos, intensivos, o que é confirmado pela seguinte assertiva: “(...) são vistos como objetos ou máquinas inanimadas, sem sentimentos, a serem manipulados, que sofrem experimentos, são fragmentados em problemas e tratados com imparcialidade. Em casos mais extremos, são isolados, alienados, despojados de sua dignidade, com pouca oportunidade de escapar do ambiente estático, estéril e degradante em que estão emaranhados"(10).

$\mathrm{Na}$ impossibilidade de o doente tomar decisões sobre seu cuidado e tratamento, tal prerrogativa deve ser exercida, por direito, pelo seu familiar, sob pena de poder acarretar grandes desgastes na relação deste com a equipe da UTI. A família, extensão do doente, com quem ele contava nos vários momentos de sua vida, é afastada do seu convívio, por imposição das rotinas do serviço, geralmente rígidas.

Quando um membro da família necessita internação numa UTI, parece ser um dos acontecimentos mais difíceis e significativos na dinâmica familiar. Essa situação se torna ainda mais difícil quando o familiar depara com um serviço em que as rotinas de visita são impostas, com horários rígidos, tempo de visita muito curto e número restrito de visitantes por doente. As informações sobre os doentes geralmente são dadas num determinado horário, pelos médicos, dificilmente pelos enfermeiros e, em alguns serviços, por meio de boletins, contendo informações do tipo: óbito; muito grave; estável; melhorando.

Pensamos poder afirmar que a internação de um parente na UTI faz com que a família geralmente se sinta alijada de todo o processo. É oportuno lembrar que essa situação não se restringe apenas à instituição de saúde, "A escola não quer a família, o hospital não quer a família, a equipe de enfermagem não quer a família, ela é apenas considerada como contexto e não instituição própria"*.

Cabe salientar que, a esse respeito, parece não haver expressiva diferença entre as instituições públicas ou privadas, o que difere é o cenário da assistência.

Em algumas UTIs, a pessoa responsável para receber o familiar, no horário de visita, limita-se a chamálo, oferecer-lhe um avental e pedir-lhe que lave as mãos. Quantas vezes, percebemos o familiar "perdido", procurando sozinho, de leito em leito, o seu parente, tendo, muitas vezes, dúvidas se estava vendo a pessoa certa, pois esta se encontrava agora com aparência bem diferente: entubado, envolto em fios, sondas, soro e aparelhos, imóvel, amarrado e despido ou, ainda, com a cabeça rapada ou enfaixada e com o rosto edemaciado.

Essa situação, para quem não recebe o menor preparo, é muito difícil. A maioria das pessoas, quando não orientadas, tem dificuldade até de se aproximar do leito, não sabe se pode ou não tocar, se pode ou não falar. A quem perguntar? Nessa hora, a Unidade parece que fica vazia, os funcionários aproveitam para tomar o café, a enfermeira, para fazer a evolução de enfermagem, e o médico, para estudar ou descansar no quarto de plantão médico. Assim agindo, os membros da equipe mostramse indiferentes aos sentimentos e às necessidades da família. A família, sentindo-se alheia e insegura, solicita ver o seu familiar doente com maior freqüência e pede informações a todo momento. A equipe, em contrapartida, reage a essa atitude, muitas vezes, com impaciência, autoritarismo e intransigência. "Famílias ansiosas, em função da gravidade da situação do paciente, ou com falta de informação, por vezes, provocam reações negativas por parte da equipe de saúde"(7).

A comunidade científica da enfermagem, insatisfeita com esse modo de cuidar, embasado somente nas ciências naturais, no modelo biomédico, iniciou, na década de 60, a elaboração de alguns modelos teóricos específicos para a prática de enfermagem. Porém, nos

\footnotetext{
* Ingrid Elsen Coordenadora do Grupo de Apoio, Pesquisa e Extensão à Família - GAPEFAM - em Palestra proferida na Jornada: Uma Reflexão Transdisciplinar da Família. Florianópolis, 1994
} 
modelos iniciais, o ser humano ainda é concebido como um ser somativo, como se fosse uma combinação de aspectos biopsicosocioespirituais suprapostos ${ }^{(11-14)}$. Assim, a enfermagem continua com uma compreensão fragmentada do ser humano. Esses modelos estão enquadrados no paradigma da totalidade, que é uma concepção aperfeiçoada da abordagem da ciência médica para a Enfermagem ${ }^{(15)}$.

No paradigma da totalidade, o ser humano é uma combinação de distintos aspectos: biológicos, psicológicos, sociais e espirituais ${ }^{(15)}$, ou seja, é um ser somativo que interage com seu ambiente interno e externo e adapta-se a ele para alcançar metas. Esse paradigma tem como pressuposto que o todo é a soma de suas partes. Novos modelos surgiram com crenças diferentes, de que a soma das partes não constitui o todo. Esses modelos foram enquadrados como paradigma da simultaneidade ${ }^{(15)}$.

\section{PARADIGMA DA SIMULTANEIDADE}

O paradigma da simultaneidade tem como pressuposto que o todo é maior que a soma de suas partes, e cada parte representa o todo. Nesse paradigma, o ser humano é um ser aberto, mais do que é diferente da soma das partes, que transforma e é transformado pelo ambiente. A saúde é o que a pessoa vive; é uma situação que tem significado somente na perspectiva da pessoa; não pode ser definida por outra pessoa. A enfermagem tem seu foco na qualidade de vida, a partir do ponto de vista da pessoa; a autoridade é a pessoa e não a enfermagem; não há planos de cuidados baseados em problemas de saúde; a enfermagem guia a pessoa a desvelar o significado da situação e, por meio de seus próprios planos, mover-se em direção à mudança de seus padrões de saúde, na melhora de sua qualidade de vida. O processo de pesquisa que testa as teorias desse paradigma é qualitativo, emprestado das ciências sociais e humanas. Nesse paradigma, encontram-se inseridos, entre outros, os modelos de duas teóricas ${ }^{(16-17)}$. Devido as suas características, foi incluído, nesse paradigma, o modelo de Paterson e Zderad que tem o diálogo como conceito central ${ }^{(18)}$ e possibilita à enfermagem conciliar razão e sensibilidade, subjetividade e objetividade no ato de cuidar.

As teóricas ${ }^{(3)}$, desde 1960, acreditavam que a enfermagem constituía-se em uma experiência existencial.
Após mais de quinze anos de estudos, observações e troca de experiência com profissionais da área, que atuavam em nível hospitalar, além de anos de vivência clínica, publicaram, em 1976, o livro Enfermagem Humanística, que se constituiu num referencial para a prática de Enfermagem. A "Enfermagem Humanística" desenvolveu-se a partir de vários questionamentos sobre como as enfermeiras interagiam e como poderiam desenvolver seus conhecimentos para a ação de enfermagem $^{(3)}$.

\section{BASES TEÓRICO-FILOSÓFICAS DA TEORIA HUMANÍSTICA DE PATERSON \& ZDERAD}

A teoria de enfermagem humanística tem suas raízes na filosofia do existencialismo, que tem influência da fenomenologia.

Os indivíduos, no existencialismo, têm possibilidades de escolha, que determinam a direção e o significado da vida de cada um. É uma abordagem filosófica para a compreensão da vida, da dimensão do SER Humano, sendo o existir a dimensão primária. Tudo se dá nesta existência e não racionalmente ${ }^{(19)}$.

Quando estamos sós, na escolha de caminhos, podemos encontrar significados ao partilhar as nossas experiências com outros que também estão enfrentando as escolhas incertas do cotidiano ${ }^{(3)}$. As autoras estão se referindo à interação, ao diálogo. A enfermagem é entendida, pelas autoras, como um diálogo vivo, por meio do qual se compreendem e se descrevem as situações de enfermagem. Para que um diálogo vivo esteja presente, há necessidade $\mathrm{da}(\mathrm{o})$ enfermeira(o) possuir conhecimentos sobre Filosofia e Ciências Humanas e procurar autoconhecimento por meio de cursos, leituras e das artes ${ }^{(3)}$. Para fundamentar a teoria da prática humanística, as teóricas utilizaram o pensamento de alguns filósofos, dentre eles, o filósofo do diálogo, Martin Buber.

Judeu existencialista, esse filósofo foi o principal expositor da filosofia dialógica - a filosofia do inter-humano, no século XX. Para ele, todo o momento da existência do ser humano é carregado de significado. O ser humano está em constante relação com outro ser, é um acontecimento histórico ${ }^{(20)}$. O colapso do relacionamento na civilização moderna foi por ele sentido. Ele tinha consciência de que a ênfase tecnocrática da sociedade 
moderna provocava um distanciamento maior entre as pessoas $^{(21)}$. Esse fato é constatado nas UTIs, visto que os profissionais, muitas vezes, como referimos anteriormente, relacionam-se mais com as máquinas do que com as pessoas que compõem o cenário nessa unidade. O ser humano, doente, familiares e profissionais, nesse ambiente, é visto apenas como um ser em si e não um ser- com- o outro. Para esse autor ${ }^{(4)}$, as relações com as pessoas se dão de duas maneiras diferentes, porém necessárias: a relação EU-TU e a EU-ISSO. A relação EU-TU é uma atitude de genuíno interesse na pessoa com quem estamos interagindo verdadeiramente como pessoa. Isso significa que valorizamos sua singularidade, reconhecendo-a como um ser existencial. Essa relação envolve a totalidade do ser, é uma relação de plenitude, de sujeitos, de intersubjetividade. A pessoa é um fim em si mesma e não um meio para atingir um fim. Em contraste, a relação EU-ISSO ocorre quando o outro é, essencialmente, um objeto para nós, utilizado como meio para um fim. Nesse tipo de relação, não existe um encontro genuíno entre pessoas. Porém, a relação EU-ISSO é um aspecto necessário na vida humana. Não é a sua existência que está "errada", mas, sim, a predominância esmagadora com que se manifesta na moderna sociedade tecnocrática ${ }^{(4)}$.

Fazendo um paralelo com a realidade do cuidado em UTI, o que se observa é que essa atitude é aplicada indiscriminadamente às situações que clamam, a todo instante, por um encontro ou diálogo genuíno entre pessoas, que somente pode emergir se duas pessoas (profissional/doente, profissional/familiar, profissional/ profissional, familiar/doente) estiverem disponíveis para ir além da atitude EU-ISSO e " valorizarem, aceitarem e apreciarem verdadeiramente a alteridade da outra pessoa"(4). Isso significa estar disponível para conhecer e entrar na esfera do entre. O "entre" é a esfera da qual todos participamos, quando estamos envolvidos e verdadeiramente interessados em outra pessoa; transcendemos o "sendo" de identidade que normalmente conhecemos. É no encontro do EU e TU que fica o reino do entre ${ }^{(4)}$.

O diálogo genuíno começa quando cada pessoa considera a outra como o ser único que é, consciente de que é um ser diferente do outro, da maneira única que lhe é peculiar ${ }^{(4)}$. Para esse autor, o reconhecimento existencial inicia-se com a validação da singularidade. A obsessão com a dimensão objetiva da existência faz com que, conseqüentemente, coisifiquemos a nós mesmos e às outras pessoas.

Alguns profissionais que atuam em UTI alegam a atitude EU-ISSO, ou "eu-coisa", como uma estratégia para o não envolvimento emocional. Nós tornamos o outro um "isso" para lidar melhor com a ansiedade que sentimos ${ }^{(21)}$. Porém, acreditamos que, embora seguro, é emocionalmente pouco compensador. Se a relação EUTU não ocorrer ocasionalmente, não somos humanos ${ }^{(4)}$. Essas duas formas de relação são essenciais para o processo de Enfermagem, sendo ambas integrantes da Teoria Humanística ${ }^{(3)}$.

\section{PRINCIPAIS CONCEITOS DA TEORIA HUMANÍSTICA DE PATERSON E ZDERAD NO CUIDADO EM TERAPIA INTENSIVA}

O ser humano é único e capaz de interagir consigo e com os outros seres, afetando o mundo e sendo afetado por ele. Possui características especiais de relacionar-se por meio da relação EU-TU, EU-ISSO, no tempo e no espaço. Na relação com outros seres, o ser humano vem a ser, e manifesta sua singularidade ${ }^{(3)}$.

O ser humano, doentes, familiares e cuidadores de enfermagem de UTI, deve ser visto como ser aberto, que interage consigo mesmo, com os outros seres e com o ambiente, ou seja, com o mundo da UTI. As relações EU-TU e EU-ISSO precisam estar presentes no ambiente da UTI, uma vez que permitem que o ser seja visto de uma maneira integral, quer na sua objetividade, na relação EU-ISSO, quer na subjetividade, na relação EU-TU. O ser humano, doente e familiares, embora vivenciem, nesse ambiente, uma experiência de risco à vida, também têm expectativas e projetos para o futuro, que precisam ser considerados pelo seres de relação. O cuidado de enfermagem, na UTI, passará a ser humanizado se houver envolvimento existencial dos cuidadores de enfermagem com o ser doente e familiares, em que vivenciam e compartilham a experiência, reconhecendo a singularidade um do outro por meio do diálogo, uma vez que tanto o ser que é cuidado, aquele que chama, quanto o ser que cuida, aquele que é chamado, sairão fortalecidos com o encontro. Ocorrendo isso, o entre será reconhecido. O ser cuidador de enfermagem precisa estar totalmente presente e, simultaneamente, ser capaz de refletir com o outro ser, sobre o que está sendo experienciado, num dado 
momento, para juntos encontrarem a solução para o problema de saúde.

O ser humano vive em dois ambientes: 0 ambiente interno, que é subjetivo, e o ambiente externo, de objetos, pessoas e coisas. É no ambiente interno que os valores, as crenças, os sentimentos nascem, e a reflexão permite a percepção desses sentimentos ${ }^{(3)}$.

O ser cuidador e o ser cuidado têm em comum uma dimensão do ambiente externo, que é a UTI, cujas características já foram comentadas na primeira parte deste trabalho, porém cada um pode perceber esse ambiente de modo diferente, influenciado pela sua vivência, pelo seu ambiente interno. A relação do ser doente (TU) com o ambiente da UTI (ISSO) será expressiva se percebida por ele como uma condição que Ihe possibilita manter ligação com o seu mundo, seu ambiente fora da UTI, que the possibilita manter ou talvez aperfeiçoar o seu ambiente interior.

O ambiente da UTI tornar-se-á menos impessoal para o doente e seus familiares quando o diálogo estiver aberto para ambos, quando houver uma interação entre os doentes e seus familiares, entre eles e o ser cuidador de enfermagem e entre os cuidadores de enfermagem da UTI. Enfim, os cuidadores de enfermagem da UTI precisam humanizar a assistência, nesse ambiente, oportunizando as relações, otimizando as expressões, tanto objetivas quanto subjetivas.

A saúde é uma questão de sobrevivência pessoal. É vivenciada no processo de viver, de estar envolvido, em cada momento, nas verdadeiras relações com os outros. Dessa forma, saúde é algo mais do que a ausência de doença. Os seres humanos possuem o potencial para o bem-estar, mas também para o estar melhor. Bem-estar refere-se a um estado de estabilidade, ao passo que estar melhor implica estar no processo de tornar-se tudo que é humanamente possível. O interesse do(a) enfermeiro(a) está no estar melhor de uma pessoa, no seu existir pleno, em ajudar o outro a ser o mais humano possível, em um momento particular de sua vida. Independente do estado geral de uma pessoa, se ela está disposta às experiências da vida, ela está saudável ${ }^{(3)}$.

Entendemos que tanto o bem-estar quanto o estar melhor devem ser os objetivos da enfermagem na UTI, e como potencial visto no doente e familiares, em qualquer área de atuação, aqui especificamente em terapia intensiva. Os(as) cuidadores(as) de enfermagem, dessa unidade, devem ajudar o outro a ser o mais humano possível (estar melhor), nesse momento particular de sua vida. Mesmo o doente de UTI estando envolto em máquinas, fios, soros, drenos, dentre outros, poderá estar melhor se a sua relação com os cuidadores de enfermagem da UTI e com os seus familiares o ajudar a encontrar sentido para a vida e para a situação vivenciada.

O diálogo é mais do que uma conversação entre duas pessoas; é um relacionamento em que ocorre um verdadeiro partilhar, uma transação intersubjetiva, isto é, a relação de um indivíduo único (EU) com outro também único $(T U)^{(3)}$.

O diálogo entre os (as) cuidadores (as) de enfermagem da UTI e o ser doente, entre os(as) cuidadores(as) de enfermagem e os familiares do doente e entre estes e o ser doente pode se dar por meio do encontro, do relacionamento, da presença, de uma chamada e uma resposta. $\mathrm{O}$ encontro entre duas pessoas ocorre quando elas atingem uma verdadeira comunhão ou comunicação. É por intermédio do encontro que o outro não é um indivíduo impessoal, um "ele" ou "ela", mas tornase um "TU" sensível e próximo do "EU"(4). O encontro verdadeiro dos cuidadores de Enfermagem com o ser doente da UTI deve estar voltado não somente para os problemas e suas soluções, mas também para a comunhão e a partilha. O encontro EU-TU (Ser cuidador) Ser cuidado) é imprescindível para que a Enfermagem preste ajuda, para que se dê o ato de Enfermagem. O encontro ocorrerá na UTI, se tanto um quanto o outro estiverem disponíveis, querendo que ele ocorra. Dar-se-á de forma efetiva, ou seja, com qualidade, se os seres envolvidos mostrarem a sua singularidade. "(...) é importante considerar a amplitude dos encontros humanos, que vão do trivial ao extremamente significante"(3).

$\mathrm{Na}$ UTI, o encontro será significante, garantindo uma autêntica intersubjetividade, quando os cuidadores de enfermagem deixarem de se esconder atrás do seu papel profissional e de exercer a dominação impondo normas e rotinas, e, ao contrário, fazer com que sua presença seja percebida pelo doente e familiares como alguém que está preocupado em compreender a sua experiência de ser doente e familiar em UTI. O encontro entre os cuidadores de enfermagem e o ser doente e familiar de UTI exige que aquele que é chamado seja, primeiro, uma pessoa disponível para outro ser humano e, segundo, um profissional com habilidade técnico-científica.

Da mesma forma que o ser doente, o ser familiar também necessita dos cuidadores de enfermagem para 
suportar a difícil situação vivenciada. Assim, neste trabalho, o ser doente e o ser familiar são considerados como sendo o ser cuidado.

No encontro dos trabalhadores de enfermagem com a família do doente, esta poderá melhorar seu estado emocional, mediante um diálogo com o uso de terminologia clara, compreensível, reservando tempo para ouvir suas preocupações e partilhar informações.

O relacionamento significa estar com o outro. Existem duas maneiras de o ser humano se relacionar: como sujeito com o objeto e como sujeito com o sujeito, ambas são elementos integrantes da enfermagem humanística ${ }^{(3)}$.

Na relação cuidadores de enfermagem/ser doente de UTI, tanto um quanto o outro podem ser vistos como sujeito (TU) ou como objeto (ISSO). Quando transformamos o outro em objeto também nos tornamos objeto $^{(19)}$. Como vimos na primeira parte deste trabalho, o doente é visto como objeto quando reduzido à vida biológica, quando considerado pelos cuidadores da enfermagem da UTI como um caso clínico, um receptáculo de procedimentos técnicos. O ser cuidado vê os cuidadores como objeto quando os considera somente executores de procedimentos. Os cuidadores são vistos como sujeitos pelo ser cuidado e vice-versa, quando existir diálogo, de forma a valorizar suas queixas, dar oportunidade para expressarem seus medos e pedir esclarecimentos, proporcionar conforto e confiança, quando respeitarem sua privacidade, demonstrarem atenção e afeição, dentre outros.

No diálogo genuíno, o ser humano relaciona-se com o outro como uma presença. Estar presente significa ser acessível ao outro, estar aberto ao outro, disponível. Essa abertura é feita a uma pessoa com necessidade. A acessibilidade deve estar dirigida a ajudar o outro. A disponibilidade significa que, além de estar à disposição do outro, está com o todo dele ${ }^{(3)}$.

A equipe de enfermagem da UTI far-se-á presente ao ser cuidado, pela competência técnica, por um olhar carinhoso, um afago, um ouvir com atenção, um tom de voz amável, dentre outros. A presença também envolve reciprocidade, os seres envolvidos no diálogo, ser cuidado e ser cuidador devem ser vistos como uma pessoa, como um EU e TU, em vez de um objeto, um ISSO.

A chamada e a resposta no diálogo da enfermagem ocorrem de forma verbal e não verbal, referemse à capacidade de os trabalhadores de enfermagem relacionarem-se com os aspectos subjetivos e objetivos da situação vivida. Ocorrem em ambas as direções ${ }^{(3)}$.

Tanto o doente quanto os(as) cuidadores(as) de enfermagem chamam e respondem. O chamado do doente de UTI tanto pode ser um pedido verbal de ajuda ao ser enfermagem quanto um pedido não verbal. A chamada não verbal poderá se dar, por exemplo, em um doente com um tubo endotraqueal, em ventilação mecânica. Nesse caso, o pedido poderá ocorrer por meio de gestos, como agitação no leito, ou por meio de sinais e sintomas, como sudorese, taquicardia, cianose, saturação de oxigênio baixa, ruídos respiratórios, etc. A resposta virá se o ser cuidador estiver atento ao diálogo, e poderá se dar, nesse exemplo, por intermédio de cuidados técnicos, como aspiração de secreção, oferta de oxigênio, solicitação da presença do médico para ajustar parâmetros no ventilador, etc. Como exemplo de um chamado do ser cuidador, podemos citar a solicitação para que o doente tussa imediatamente, após ser retirado o tubo endotraqueal. Se o paciente atender à solicitação significa que houve resposta, houve o diálogo. Esses exemplos correspondem à objetividade do ser. Como chamado e resposta atendendo à subjetividade, podemos citar, como exemplo, a chamada freqüente do ser cuidador pelo ser cuidado a qual pode denotar necessidade da presença de um outro ser, medo, insegurança, e, quando atendida com a efetiva presença do ser cuidador, dar-se-á o diálogo. O ser cuidador, ao responder ao chamado, estará também chamando o doente para uma participação no diálogo e vice-versa.. Quando ignoramos o chamado, não percebemos, muitas vezes, o de que realmente necessita o doente que pode estar na expressão da subjetividade. Com relação ao ser familiar, os(as) cuidadores(as) de enfermagem deverão se mostrar presentes, ouvindo o seu chamado, na expectativa de dar uma resposta condizente com as suas necessidades, concretizando, dessa forma, o diálogo.

A Enfermagem é uma resposta de cuidado a um chamado de ajuda que se dá por meio da compreensão do significado de experiências de vida e busca de potenciais. Durante o encontro, a relação inter-humana estará intencionalmente voltada para o bem-estar e o estar melhor. A Enfermagem, portanto, é um diálogo vivido, em que a(o) enfermeira(o) e outra pessoa relacionam-se pelo encontrar-se, pelo estar presente. Para entendê-la, é necessário considerá-la como um fenômeno que ocorre 
no mundo real das vivências humanas, variando conforme o doente, sua idade, a situação clínica, sua incapacidade etc., bem como a percepção do(a) enfermeiro(a) acerca da necessidade e suas atitudes para responder a ela ${ }^{(3)}$.

Os(as) cuidadores(as) de Enfermagem da UTI estarão exercendo a enfermagem, conforme o paradigma da simultaneidade, se estiverem disponíveis ao diálogo, à compreensão do que significam para o ser doente e seu familiar as experiências vivenciadas, durante a internação na UTI, se estiverem dispostos a ir além da competência técnica, ao encontro do outro, a conhecer aquele que chama como um ser singular.

A Enfermagem em UTI estará alicerçada pelo paradigma da simultaneidade se não seguir planos de cuidados preestabelecidos, baseados somente em problemas gerais, comuns. Os planos deverão, sim, ser individuais, mutuamente estabelecidos, para que possam ajudar o ser cuidado a desvelar o significado da experiência e melhorar sua qualidade de vida para o alcance do bemestar e estar melhor. Será considerado um modo dialogal de ser, em uma situação intersubjetiva, se tanto o ser cuidador quanto o ser cuidado forem percebidos entre si como seres singulares.

\section{REFERÊNCIAS BIBLIOGRÁFICAS}

1. Kuhn TS. A estrutura das revoluções científicas. $2^{a}$ ed. São Paulo (SP): Perspectiva; 1982.

2. Guba EG, Lincoln YS. Competing paradigms in qualitative research In: Denzim N, Lincoln YS. Handbook of qualitative research. London: Sage Publications; 1994.

3. Paterson JG, Zderad LT. Humanistic nursing. 2rd ed. New York (NY): National League for Nursing; 1988.

4. Buber M. Eu e Tu. 2a ed. São Paulo (SP): Moraes; 1974.

5. Espirito Santo TJM. Segurança emocional como necessidade humana básica - atuação do enfermeiro junto ao cliente em unidade de terapia intensiva. Rev Bras Enfermagem 1985 julho/dezembro; 38(3/4):231-7.

6. Galiza MC. Estudo das necessidades dos clientes internados em UTI. Enfoque 1985 dezembro; 13(2):29-32.

7. Waldow VR. Cuidado humano: o resgate necessário. Porto Alegre (RS): Sagra Luzzatto; 1998.

8. Vila VSC, Rossi LA. O significado cultural do cuidado humanizado em unidade de terapia intensiva: muito falado e pouco vivido. Rev Latino-am Enfermagem 2002 março-abril; 10(2):137-44.

9. Polak YNS. O corpo como mediador na relação homem/ mundo. Texto \& Contexto Enfermagem 1997 setembro/ dezembro; 6(3):29-43.

10. Marsden C. An ethical assessment of intensive care. J Technol Assessment Healt Care 1992; 8(3):408-18.

11. Horta WA. Processo de enfermagem.São Paulo (SP): EPU; 1979.

Recebido em: 19.4.2002

Aprovado em: 29.10.2003

\section{CONSIDERAÇÕES FINAIS}

Enfim, acreditamos que o paradigma da simultaneidade, como forma de perceber o ser humano hospitalizado em UTI, possibilita um cuidado que rompe com o modelo assistencial predominante, cujo objetivo maior é a cura e não o cuidado do ser.

Não desconsideramos, em hipótese alguma, a importância do atendimento à expressão da objetividade do ser, pensamos, sim, que esta deva estar atrelada à subjetividade.

Precisamos romper o estereótipo concentrado no técnico em assistência intensiva e voltar a atenção principalmente para a pessoa do doente e seu familiar. Manter além do relacionamento EU-ISSO, o relacionamento EU-TU, é característica de uma enfermagem comprometida com o mais ser do doente e seu familiar.

A enfermagem da UTI precisa estar atenta para perceber como o doente e o seu familiar vivenciam o encontro EU-TU, EU-ISSO, em um ambiente adverso ao seu, de modo a torná-lo o mais favorável possível à recuperação da saúde.

12. King IM. A theory for Nursing: systems, concepts, process. New York (NY): John Wiley; 1981.

13. Roy SC. Introduction to Nursing :and adaptation model. Englewood Cliffs (NJ): Prentice-Hall; 1976.

14. Orem DE. Nursing: concepts of practice. 3rd ed. New York: McGraw-Hill; 1985.

15. Parse RR. Nursing Science: Major paradigms, theories and critiques. Philadelphia: W B Saunders; 1987.

16. Rogers ME. An introduction, the theoritical basis of Nursing.14rd ed. Philadelphia: FA Davies; 1985.

17. Parse RR. Man-living-health: a theory of nursing. New York: Wiley; 1981

18. Souza LNA. A interface da comunicação entre a enfermagem e os clientes em uma unidade de terapia intensiva. [dissertação]. Florianópolis (SC): Programa de PósGraduação em Enfermagem/UFSC; 2000.

19. Praeger SG, Hogarth CR. Josephine E. Paterson e Loretta T. Zderad. In: Julia BG, organizadora. Teorias de enfermagem: os fundamentos para a prática profissional. Porto Alegre (RS): Artes Médicas; 1993. p.242-53.

20. Sidekum A. A intersubjetividade em Martin Buber. Porto Alegre (RS): EST/UCS; 1979.

21. Hycner R. De pessoa a pessoa: psicoterapia dialógica. São Paulo (SP): Summus; 1995. 